\title{
MAGNESIUM SULFATE EVOKES ENDOTHELIUM-INDEPENDENT RELAXATION IN THE CHICKEN DUCTUS ARTERIOSUS
}

\author{
Y. Dias-Guichot, E. Verver, S. van der Sterren, E. Villamor
}

Pediatrics, Maastricht University Medical Center (MUMC+), GROW School, Maastricht, The Netherlands

Background and aims: Magnesium sulfate $\left(\mathrm{MgSO}_{4}\right)$ is widely used as tocolytic agent and for the prophylaxis of seizures in pre-eclampsia. Antenatal exposure to $\mathrm{MgSO}_{4}$ has been associated with a higher risk of patent DA in preterm infants. $\mathrm{MgSO}_{4}$ is a vasodilator and thus may exert a direct relaxant effect in the DA. Here we aimed to investigate the possible vasoactive effects of $\mathrm{MgSO}_{4}$ in the chicken DA.

Design/methods: Isolated rings of the DA from 15-d (E15) and 19-d (E19) chicken embryos (total incubation: 21-d) were mounted in a wire myograph for isometric tension recordings. Rings were precontracted with $21 \% \mathrm{O}_{2}$, norepinephrine $(\mathrm{NE}, 1 \mu \mathrm{M})$ or $\mathrm{KCl}(62.5 \mathrm{mM})$.

Results: $\mathrm{MgSO}_{4}(2.4-7.2 \mathrm{mM}$ ) elicited a concentration-dependent relaxation (mean maximal relaxation: $56.7 \%$, SD 41.8; $\mathrm{EC}_{50}: 2.9 \mathrm{mM}, \mathrm{SD} 0.3$ ) of $\mathrm{O}_{2}$-induced active tone in $\mathrm{E} 19 \mathrm{DA}$ rings. $\mathrm{MgSO}_{4}$ also relaxed NE-contracted (with similar efficacy but lower potency than $\mathrm{O}_{2}$-contracted) and $\mathrm{KCl}$-contracted (with lower efficacy and potency) $\mathrm{E} 19 \mathrm{DA}$ rings. $\mathrm{MgSO}_{4}$-induced relaxation of $\mathrm{KCl}$-contracted $\mathrm{DA}$ rings was not significantly different between E15 and E19. Endothelium removal or the presence of the NO synthase inhibitor L-NAME, the soluble guanylate cyclase inhibitor ODQ, the cyclooxygenase inhibitor indomethacin, or the sarcoplasmic reticulum $\mathrm{Ca}^{2+}$-ATPase inhibitor thapsigargin did not significantly modify $\mathrm{MgSO}_{4}$-induced relaxation. The relaxant effect of $\mathrm{MgSO}_{4}$ was reversed by increasing the extracellular $\mathrm{Ca}^{2+}$ concentration.

Conclusions: $\mathrm{MgSO}_{4}$, at clinically relevant concentrations, induces endothelium-independent relaxation of chicken DA. This relaxant effect may be due to inhibition of $\mathrm{Ca}^{2+}$ entry from extracellular space. 